\title{
Pharmacognosy \\ Development of a gas chromatography method for quantification of triterpenes in the commercial oleoresins from Protium species
}

\author{
Gabrielle Pereira das Neves ${ }^{1}$, Marcos Jun Nakamura ${ }^{1}$, Mônica Freiman de Souza Ramos ${ }^{2}$, \\ Antonio Carlos Siani ${ }^{1}$ \& José Luiz Mazzei ${ }^{1,3,4}$
}

\begin{abstract}
Crude non-volatile oleoresin from Burseraceae species ( $\mathrm{breu}$ ), a non-timber forest product of the Amazon, still lacks methods for its quality control even though its pharmacological activities have been associated to the major triterpenes $\alpha$-amyrin ( $\alpha \mathrm{AA}$ ), $\beta$-amyrin, $\alpha$-amyrenone, $\beta$-amyrenone and lupeol (LU). Its chemical characterization has usually been determined by gas chromatography (GC) using columns with phases of low polarity, which are ineffective in the separation of $\alpha \mathrm{AA}$ and LU. The present study aimed to develop a GC method to characterize and quantify triterpenes in commercial breu with good selectivity and resolution. Columns with phases of different polarity (DB-35, DB-1701, DB-17HT and DB-Innowax) were tested, and DB-17HT separated $\alpha$ AA and LU without signal suppression or high retention of other constituents. This column allowed the quantification of breu triterpenes using flame ionization detection and cholesterol as a reference standard. Good similarity between the calibration curves of cholesterol and $\alpha$ AA was verified. Internal and external standardizations led to different $(p<0.05)$ quantifications, but the latter showed less deviation (RSD $\leq 3 \%$ ). This work provides a reproducible GC method for the quality control of commercial breu, clearly evidencing the presence of lupeol and allowing the accurate quantification of major triterpenes. Key words: gas chromatography, oleoresin, Protium, quantification, triterpenes.

\section{Resumo}

A oleorresina bruta não volátil das espécies de Burseraceae ( $b r e u)$, um produto florestal não madeireiro da Amazônia, ainda carece de métodos para seu controle de qualidade, embora suas atividades farmacológicas tenham sido associadas aos principais triterpenos $\alpha$-amirina ( $\alpha \mathrm{AA}$ ), $\beta$-amirina, $\alpha$-amirenona, $\beta$-amirenona e lupeol (LU). Sua caracterização química tem sido geralmente determinada por cromatografia gasosa (CG), utilizando colunas com fases de baixa polaridade, que são ineficazes na separação de $\alpha$ AA e LU. O presente estudo teve como objetivo desenvolver um método de CG para caracterizar e quantificar triterpenos em breu comercial com boa seletividade e resolução. Colunas com fases de diferentes polaridades (DB-35, DB1701, DB-17HT e DB-Innowax) foram testadas, e DB-17HT separou $\alpha$ AA e LU sem supressão de sinal ou alta retenção de outros constituintes. Esta coluna permitiu a quantificação de triterpenos do breu utilizando detecção de ionização de chama e colesterol como padrão de referência. A boa similaridade entre as curvas de calibração do colesterol e $\alpha$ AA foi verificada. Padronizações interna e externa levaram a quantificações diferentes $(p<0,05)$, mas a última apresentou menor desvio ( $\mathrm{RSD} \leq 3 \%)$. Este trabalho fornece um método de CG reprodutível para o controle de qualidade do breu comercial, evidenciando claramente a presença do lupeol e permitindo a quantificação precisa dos principais triterpenos.

Palavras-chave: cromatografia a gás, oleorresina, Protium, quantificação, triterpenos.
\end{abstract}

\footnotetext{
${ }^{1}$ Fundação Oswaldo Cruz, Inst. Tecnologia em Fármacos, Depto. Produtos Naturais, R. Sizenando Nabuco 100, Manguinhos, 21041-250, Rio de Janeiro, RJ, Brazil.

${ }^{2}$ Universidade Federal do Rio de Janeiro, Faculdade de Farmácia, Depto. Fármacos e Medicamentos, Av. Carlos Chagas Filho 373, Ilha do Fundão, 21941-902, Rio de Janeiro, RJ, Brazil.

${ }^{3}$ ORCID: <https://orcid.org/0000-0002-2009-0053>

${ }^{4}$ Author for correspondence: mazzei@pq.cnpq.br
} 


\section{Introduction}

Oleoresins produced by species of Burseraceae Kunth, popularly known as breu or almécega (Hernández-Vázquez et al. 2010), are among the Amazonian non-timber forest products (NTFP) with the highest commercial potential. These materials are mainly sourced from species of Protium Burm.f. and closely related genera (Rüdiger \& Veiga-Junior 2013).

The Amazonian breu is primarily constituted by a mixture of triterpenes and volatile monoterpenes (Langenheim 2003). The latter are usually separated by submitting the raw material (as fresh as possible) to steam distillation (Siani et al. 1999). The resulting essential oil is demanded by perfumery and diverse pharmaceutical products (Costa 1975), besides presenting a wide range of biological properties (Murthy et al. 2016). Conversely, the solid residue product of distillation is constituted by the crude triterpene fraction, resembling the hard breu collected from the soil beneath the oleoresin-producing tree, where it ages after spontaneous detachment from the tree branches (Siani et al. 2012). It has been reported that the commercial oleoresins of breu have usually presented exclusively a mixture of triterpenes (Siani et al. 1999). This material is a solid that eventually is softened by heating into an amorphous material able to caulk boats, repair wooden objects and act as an excellent film-forming constituent in varnish and waterproofing agent (Costa 1975; Ramos et al. 2000).

Although imbued with high potential for commercialization, this dry raw material is sold at low prices in local markets scattered throughout the Amazonian region. Adding value to the Amazonian breu would require organization of its production niche and amelioration of the already existing initiatives aiming at exploiting it from this source (UNDP 2012; Silva et al. 2016). In this context, the developing methods is an important step to qualify the raw material chemically and to propose some level of standardization for such a raw material (Siani et al. 2017).

Efforts have been exerted for establishing the chemical profile of the non-volatile fraction of breu, which is mostly constituted by a mixture of the pentacyclic triterpene alcohols $\alpha$-amyrin and $\beta$-amyrin (Hernández-Vázquez et al. 2010), complemented with the corresponding ketones as well as minor amounts of diols and acidic tetracyclic species (Susunaga et al. 2001; Vieira
Júnior et al. 2005; Siani et al. 2012; Rüdiger $\&$ Veiga-Junior 2013). These major amyrins have been reported as responsible for the antiinflammatory, antinociceptive, hepatoprotective and gastroprotective activities of breu (Rüdiger et al. 2007; Aragão et al. 2008; Melo et al. 2011).

Gas chromatography (GC) with columns using low polarity stationary phases, composed of polydimethylsiloxanes with 1 to $5 \%$ phenyl groups, has been usually applied for the chemical analysis of breu. This probably occurs because these columns are efficient in separating the monoterpenes and sesquiterpenes present in the volatile fraction of this oleoresin (Ramos et al. 2000; Siani et al. 2012; Satyal et al. 2017), which has been extensively studied in view of its versatility of applications for the cosmetic industries. Thus, there is a clear tendency to reproduce these analytical conditions in the characterization of the non-volatile fraction of breu, which is rich in triterpenes (Maia et al. 2000; Guimarães \& Siani 2007; Silva et al. 2009; Siani et al. 2012; Lima et al. 2014). However, such stationary phases imply coelution of the $\alpha$-amyrin and lupeol, which become indistinguishable when using flame ionization detection (FID) and thus require a mass spectrometry detector for the quantification of these compounds, as seen for other matrices (Moggia et al. 2016). In fact, the GC-FID method has not been reported for assay of triterpenes so far. In this way, the present study aims to develop a feasible GC-FID method to quantify the triterpenoid components in this important NTFP.

\section{Material and Methods}

Oleoresin, chemicals and GC columns A commercial sample (3 kg) of raw breu was acquired in a popular market in the municipality of Manaus, Amazonas state, Brazil, in 2001. The material was stored in proper cardboard containers that were maintained in dry places until its utilization.

HPLC/UV grade chloroform (99.8\% purity) and dichloromethane were purchased from Tedia (Fairfield, USA). Analytical grade diethyl ether was acquired from Vetec (Rio de Janeiro, Brazil). Cholesterol (95\%) and $\alpha$-amyrin $(\geq 98 \%)$ were furnished by Sigma Aldrich (Missouri, USA).

Columns with stationary phases (Agilent, California) of different polarity were applied: three based on polydimethylsiloxane, DB-35 (35\% phenyl, $30 \mathrm{~m} \times 250 \mu \mathrm{m} \times 0.25 \mu \mathrm{m}$ film thickness), 
DB-1701 (14\% cyanopropyl-phenyl, $30 \mathrm{~m} \times 320$ $\mu \mathrm{m} \times 0.25 \mu \mathrm{m})$, and DB-17HT (50\% phenyl, $30 \mathrm{~m} \times$ $250 \mu \mathrm{m} \times 0.15 \mu \mathrm{m}$ ), and one based on polyethylene glycol, DB-Innowax $(30 \mathrm{~m} \times 250 \mu \mathrm{m} \times 0.25 \mu \mathrm{m})$.

\section{Pretreatment of the oleoresin}

The commercial hard oleoresin was fragmented into small pieces with the aid of a hammer and then manually pulverized with a pestle in a porcelain mortar. The powdered breu was mechanically sieved through a set of stainless sieves (Bertel, Brazil), and particles with sizes below 32 mesh $(500 \mu \mathrm{m})$ were selected and conditioned at room temperature in an amber glass vessel. This was labeled as Processed Breu Oleoresin (PBO). The percent moisture level was determined in an automatic digital drying scale (Marte ID series 1.8, model ID50), subjecting a 1 g-sample to $105^{\circ} \mathrm{C}$ in a quartz-coated infrared heat source until reaching constant weight. The melting point was determined through digital equipment (MQAPF-302 model, Microquímica, Palhoça, Brazil) at the heating rate of $5{ }^{\circ} \mathrm{C} / \mathrm{min}$.

\section{Gas chromatography with flame} ionization detection (GC-FID)

GC-FID was performed in an Agilent 6890N chromatograph equipped with an autoinjection system (Agilent 7683) (Palo Alto, CA, USA). Hydrogen as carrier gas at constant flow rate of 1.8 $\mathrm{mL} / \mathrm{min}$; injector set at $290^{\circ} \mathrm{C}$ and split ratio $1: 25$; and injection volume of $1.0 \mu \mathrm{L}$. Oven temperature ranged from $50^{\circ} \mathrm{C}$ (held for 5 minutes) to $230^{\circ} \mathrm{C}$ at $20^{\circ} \mathrm{C} / \mathrm{min}$, followed by $5{ }^{\circ} \mathrm{C} / \mathrm{min}$ until $350^{\circ} \mathrm{C}$ (held for 9 minutes). The detector was set at $400{ }^{\circ} \mathrm{C}$ and was operated with air at $320 \mathrm{~mL} / \mathrm{min}$, hydrogen at $31 \mathrm{~mL} / \mathrm{min}$ and nitrogen at $10 \mathrm{~mL} / \mathrm{min}$.

The calibration curve of cholesterol was built by triplicate injections at eight concentration levels: $2.5,5.0,10.0,50.0,100,250,400$, and $500 \mu \mathrm{g} / \mathrm{mL}$. FID did not respond linearly to a $1000 \mu \mathrm{g} / \mathrm{mL}$ solution that was also injected. The individual concentrations of the triterpenes in sample dilutions were calculated by external standardization, considering the parameters of the linear equation, which were estimated by the least-squares method of the calibration curve of cholesterol (external standard, ES). Concentrations in PBO were determined considering the standard purity and the weight and moisture of the sample. The sensibility of the method was verified by comparing the calibration curve of ES with that obtained from $\alpha$-amyrin in the same working range $(2.5-500 \mu \mathrm{g} / \mathrm{mL})$.

The limit of detection $(0.4 \mu \mathrm{g} / \mathrm{mL})$ and the limit of quantitation $(1.3 \mu \mathrm{g} / \mathrm{mL})$ were determined from three other calibration curves (ICH 1997) which were built with cholesterol dilutions at 1.0, $2.5,5,10$, and $50 \mu \mathrm{g} / \mathrm{mL}$.

The PBO $(100 \mathrm{mg})$ was weighed at 0.1 precision in a $100 \mathrm{~mL}$ volumetric flask and completely dissolved with $\mathrm{CHCl}_{3}$, giving a clear solution and so filtration was not performed to avoid concentration errors due to solvent evaporation. Sample dilutions were prepared in triplicate. For studying the application of internal standardization, a $0.1 \mathrm{mg} / \mathrm{mL}$ cholesterol solution in $\mathrm{CHCl}_{3}$ was applied as solvent for other three weightings.

\section{Gas chromatography with mass spectrometry (GC-MS)}

The samples were completely dissolved at 1 $\mathrm{mg} / \mathrm{mL}$ in $\mathrm{CHCl}_{3}$ at room temperature and placed in sealed $1.5 \mathrm{~mL}$ vials. The individual constituents of PBO were identified by GC using a chromatograph of the same model as that in GC-FID, but equipped with an Agilent 5973N mass spectrometer (Palo Alto, CA, USA). Runs were performed in the DB$17 \mathrm{HT}$ column with helium as carrier gas at flow rate of $1.0 \mathrm{~mL} / \mathrm{min}$. The injector was set at 250 ${ }^{\circ} \mathrm{C}$, and the split ratio was $1: 10$. Oven temperature was programmed as for the GC-FID procedure. Ion source, transfer line and quadrupole were set at 250,290 and $150{ }^{\circ} \mathrm{C}$, respectively, with electron impact ionization at $70 \mathrm{eV}$. Acquisition mass ranged from 70 to $800 \mathrm{Da}$.

The constituents were identified by comparing their fragmentation patterns to those of the Wiley 275 library (Agilent MSD Productivity ChemStation) and to those found in the literature (including fragmentation pathways) and other mass spectral reference libraries (Vilegas et al. 1997; Noronha 2001; Carvalho et al. 2010; HMDB 2017; NIST 2017; SDBS 2017).

\section{Results and Discussion}

The raw commercial oleoresin from a popular market was characterized as a mechanically resistant dark solid. After cracking, the remaining wood debris and other inorganic impurities from the tree trunks commonly present in the collected oleoresin (Siani et al. 2012) were removed off. The resulting material $(3 \mathrm{~kg})$ was divided in fine 
particles by sieving (PBO, $2.5 \mathrm{~kg}$ ) that presented $1.75 \%(\mathrm{w} / \mathrm{w})$ average humidity and melted at $100-120^{\circ} \mathrm{C}$.

GC-FID was applied for chemically characterizing and checking the separation performance of the PBO components using different columns. Initially, the programming of the column oven was based on a previous study (Siani et al. 2012), in which the authors used a DB-5 column, but poor separation efficiency was found for two of the interesting triterpenes, $\alpha$-amyrin and lupeol, and several other expected minor peaks. Any pre-treatment to remove monoterpenes and sesquiterpenes was spared since these compounds elute below $200{ }^{\circ} \mathrm{C}$, as also shown by Satyal et al. (2017), and so do not interfere with the signals of triterpenes (elution above $290{ }^{\circ} \mathrm{C}$ ). Thus, GC-FID analyses of PBO in columns with other stationary phases (DB-35, DB-1701, DB-17HT and DB-Innowax) were performed, and typical chromatograms are presented in Figure 1a-d. Among the columns based on phenyl methylpolysiloxane phases DB-5, DB-35 and DB-17HT - the latter proved to present the best separation efficiency, evidencing minority compounds around main peaks and the elution of more retained compounds (retention time of $28-30 \mathrm{~min})$. The DB-35 column also shows improved resolution for the interesting triterpenes, comparatively to DB-5, but with worst resolution
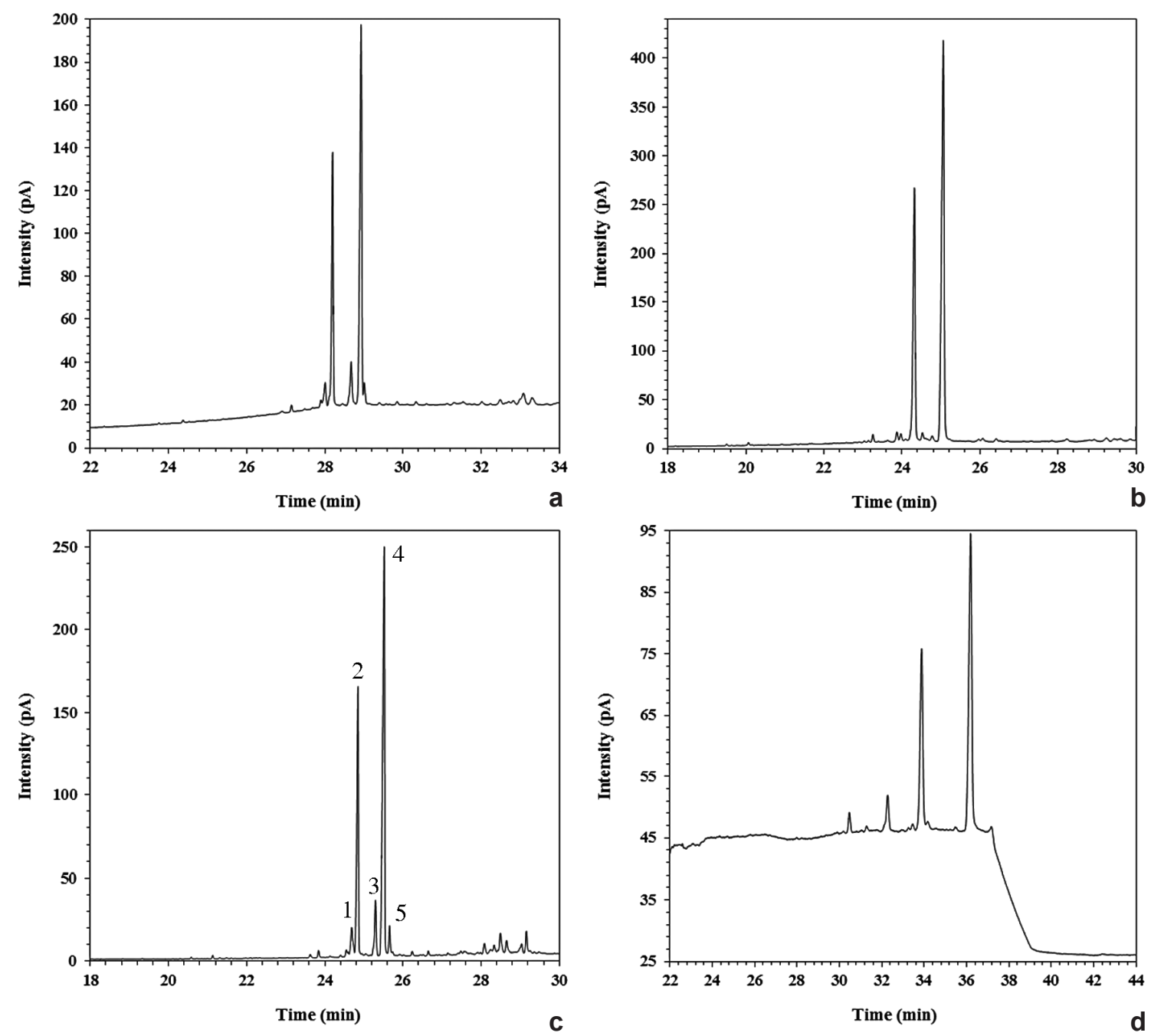

Figure 1 - a-d. Typical GG-FID chromatograms of breu in different stationary phases - a. DB-35; b. DB-1701; c. DB-17HT, with peaks of major triterpenes assigned as identified by GC-MS (Tab. 1); d. DB-Innowax. 
than the DB-17HT column. There was evidence of intensity suppression of minorities at times around the main signals on the DB-1701 column. Finally, the most polar DB-Innowax column resulted in only four relevant signals in the PBO chromatogram with prolonged run time, probably due to their strong interaction with the triterpenes that would lead to interference in subsequent runs. Thus, in view of the resolution between $\alpha$-amyrin and lupeol without signal suppression and lack of resolution among the other main triterpenes, the DB-17HT column was considered as the most suitable to analyze breu by GC, being thus selected for further development.

It was possible to assign the five wellresolved triterpenes of $\mathrm{PBO}$ in Figure 1 through GC-MS analysis using the DB-17HT column (Tab. 1): $\beta$-amyrenone, $\beta$-amyrin, $\alpha$-amyrenone, $\alpha$-amyrin, and lupeol. The presence of these substances corroborates the literature reporting isolated lupeol in breu oleresin (Maia et al. 2000; Guimarães \& Siani 2007), but it has not been detected directly by any analytical method so far.

It is important to note that, as a general rule, oleanane-type triterpenes elute before their ursane isomers, as observed by retention times on low and medium polarity columns (Siani et al. 1999; Maia et al. 2000). In the present study, this feature was considered to punctuate the identities of the triterpenes, besides the respective mass fragmentations. This assertion is also corroborated by the usual predominance of $\alpha$-amyrin on $\beta$-amyrin, and reproduced for the corresponding ketones ( $\alpha$-amyrenone on $\beta$-amyrenone) in breu (Maia et al. 2000; Guimarães \& Siani 2007; Silva et al. 2009; Siani et al. 2012; Lima et al. 2014; Melo et al. 2019). In fact, the retention time of $\alpha$-amyrin in PBO (25.5 min) was verified with that obtained through injection of standard.

The quantification of $\mathrm{PBO}$ components was performed through GC-FID, using cholesterol as ES. The equation of the calibration curve was determined as $\mathrm{y}=0.961 \mathrm{x}-12.772$, where $\mathrm{y}$ is equal to the integration area of the cholesterol signal and $\mathrm{x}$ corresponds to the concentration of the ES in $\mu \mathrm{g} /$ $\mathrm{mL}$. The linear Pearson's correlation (r) equal to 0.996 and the relative standard deviation (RSD) $\leq$ $1.0 \%$ were in compliance with ICH criteria of $r>$ 0.990 and $\mathrm{RSD}<5 \%$ (ICH 1997).

Cholesterol was selected as ES in view of (i) commercial availability of the certified material, (ii) lower market value (approximately 200 -fold) than the amyrin isomer standards, and (iii) structural similarity (Lanças 2009) to the majority of pentacyclic triterpenes in breu, which FID response can be very similar to the analyte (Dietz 1967). In fact, this chemical has already been applied previously as internal standard for the quantification by $\mathrm{GC}$ of oleanolic acid, ursolic acid, $\alpha$-amyrin, and lupeol in blueberry cutine. However, mass spectrometry (MS) detection was necessary for quantification of these compounds in view of the analysis having been performed in a low polarity column (Elite-5MS), similar to DB-5 (Moggia et al. 2016). Moreover, a verification of similarities between the response factors by the detection of cholesterol and triterpenes should be necessary to demonstrate the accuracy of the use of ES for purposes of quantification of triterpenes in breu.

In our study, the standard was applied as ES because this procedure consumes less chemical material and extractive steps were not required, which implies enhanced recovery. Moreover, our

Table 1 - Fragmentation by GC-MS and quantification of the main triterpenes found in PBO by the proposed GCFID method using DB-17HT column and standardization with cholesterol.

\begin{tabular}{lccccc}
\hline Peak $^{*} \begin{array}{c}\mathbf{t}_{\mathbf{R}} \\
(\mathbf{m i n})\end{array}$ & $\mathbf{m} / \mathbf{z}$ & Compound & \multicolumn{2}{c}{ By standardization } \\
\cline { 4 - 7 } & 24.68 & $281(100), 133,147,95,424\left[\mathrm{M}^{+}\right], 409$ & $\beta$-amyrenone & $2.38 \pm 0.07$ & $1.91 \pm 0.23$ \\
\hline 1 & 24.85 & $218(100), 203,189,175,95,135,161,426\left[\mathrm{M}^{+}\right], 411$ & $\beta$-amyrin & $9.28 \pm 0.26$ & $8.14 \pm 0.98$ \\
2 & 25.30 & $281(100), 133,147,95,424\left[\mathrm{M}^{+}\right], 409$ & $\alpha$-amyrenone & $3.27 \pm 0.08$ & $2.71 \pm 0.32$ \\
3 & 25.52 & $218(100), 203,189,175,95,135,161,426\left[\mathrm{M}^{+}\right], 411$ & $\alpha$-amyrin & $18.93 \pm 0.57$ & $16.87 \pm 2.06$ \\
4 & 25.66 & $218(100), 95,189,107,109,121,135,203,426\left[\mathrm{M}^{+}\right], 411$ & lupeol & $4.52 \pm 0.11$ & $3.85 \pm 0.46$ \\
\hline
\end{tabular}

* Peaks assigned in the Fig. 1c. $t_{\mathrm{R}}=$ Retention time. Determination by weighing in triplicate. Compounds identified by the fragmentation patterns in the literature (Vilegas et al. 1997; Noronha 2001; Carvalho et al. 2010) and in the mass spectral reference libraries Wiley 275 (Agilent), HMDB (2017), NIST (2017) and SDBS (2017). 
method involves a less costly and more readily available detector (FID in place of MS), which is also more suitable in terms of similarity of response between the ES and the intended analytes. Nonetheless, the similarities between response factors were checked by FID in the present study. The analytical curves of $\alpha$-amyrin $(\mathrm{y}=1.061 \mathrm{x}$ - 6.679, r 0.999, RSD $\leq 0.52 \%$ ) and cholesterol indicated very similar sensitivities by FID (Fig. 2). The ratio between both sensitivities is equal to 1.027 , closer than one unit $(<3 \%$ error), indicating excellent accuracy in using cholesterol as a reference for quantification of triterpenes.

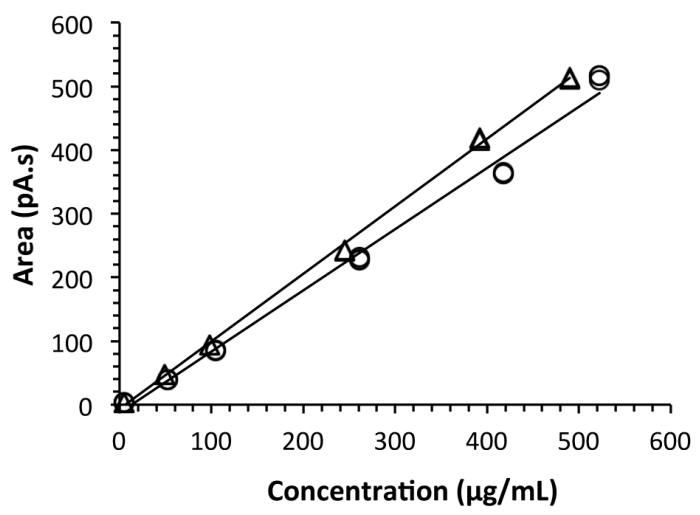

Figure 2 - Analytical curves of cholesterol (circles) and $\alpha$-amyrin (triangles).

Table 1 shows the quantification by external standardization and by internal standardization of the main triterpenes found in the PBO. The quantitation methods indicate different $(p<0.05)$ individual content, through a paired $t$-test (twotailed), however, the external standardization is preferred in view of its lower uncertainty (low $\%$ RSD). The standardization using cholesterol is quite advantageous in comparison with the technique of area normalization, which was determined by the ratio between individual and total integration areas (Grinberg \& Rodriguez 2019) and improperly overestimated (2.5-times higher) the content of triterpenes (data not shown).

\section{Acknowledgements}

The authors are grateful to Dr. Marcelo Raul Romero Tappin (Institute of Drug Technology/ Fiocruz) for valuable suggestions and to the Department of Analytical Methods of the Institute of Drug Technology/Fiocruz for technical support. This study was financially supported by National Council for Scientific and Technological Development (CNPq, Proep/CNPq-Far/Fiocruz 407841/2017-2).

\section{References}

Aragão GF, Pinheiro MCC, Bandeira PN, Lemos TLG \& Viana GSB (2008) Analgesic and anti-inflammatory activities of the isomeric mixture of alpha-and betaamyrin from Protium heptaphyllum (Aubl.) March. Journal of Herbal Pharmacotherapy 7: 31-47.

Carvalho TC, Polizeli AM, Turatti ICC, Severiano ME, Carvalho CE, Ambrósio SR, Crotti AEM, Figueiredo US, Vieira PC \& Furtado NAJC (2010) Screening of filamentous fungi to identify biocatalysts for lupeol biotransformation. Molecules 2010: 6140-6151.

Costa AF (1975) Farmacognosia. Vol. 1. Fundação Calouste Gulbenkian, Lisboa. Pp. 841-842.

Grinberg N \& Rodriguez S (2019) Ewing's analytical instrumentation handbook. $4^{\text {th }}$ ed. CRC Press, Boca Raton. 646p.

Dietz WA(1967) Response factors for gas chromatographic analyses. Journal of Chromatographic Science 5: 68-71.

Guimarães AC \& Siani AC (2007) Triterpenes from the leaves of Protium strumosum. Revista Fitos 3: 67-76.

Hernández-Vázquez L, Mangas S, Palazón J \& NavarroOcaña A (2010) Valuable medicinal plants and resins: commercial phytochemicals with bioactive properties. Industrial Crops and Products 31: 476480.

HMDB - The Human Metabolome Database (2016) The metabolomics innovation centre. Available at <http://www.hmdb.ca/spectra/c_ms/search $>$. Access on 10 November 2017.

ICH - Internacional Conference on Harmozination (1997) Guide for industry: Q2B validation of analytical procedures: methodology. Current Step 4 version dated 19 may 1997. Available at <https://www.fda. gov/regulatory-information/search-fda-guidancedocuments/q2b-validation-analytical-proceduresmethodology >. Access on 10 October 2017.

Lanças FM (2009) A cromatografia líquida moderna e a espectrometria de massas: finalmente "compatíveis"? Scientia Chromatographica 1: 35-61.

Langenheim JH (2003) Plant resins: chemistry, evolution and ethnobotany. Timber Press, Portland. 612p.

Lima EM, Nascimento AM, Lenz D, Scherer R, Meyrelles SS, Boëchat GAP, Andrade TU \& Endringer DC (2014) Triterpenes from the Protium heptaphyllum resin - chemical composition and cytotoxicity. Brazilian Journal of Pharmacognosy 24: 399-407. 
Maia RM, Barbosa RP, Cruz FG, Roque NF \& Fascio M (2000) Triterpenos da resina de Protium heptaphyllum March (Burseraceae): caracterização em misturas binárias. Química Nova 23: 623-626.

Melo CM, Morais TC, Tomé AR, Brito GAC, Chaves MH, Rao VS \& Santos FA (2011) Anti-inflammatory effect of $\alpha, \beta$-amyrin, a triterpene from Protium heptaphyllum, on cerulein-induced acute pancreatitis in mice. Inflammation Research 60: 673-681.

Melo KM, Oliveira FTB, Silva RAC, Quinderé ALG, Marino Filho JDB, Araújo AJ, Pereira EDB, Carvalho AA, Chaves MH, Rao VS \& Santos FA (2019) $\alpha, \beta$-Amyrin, a pentacyclic triterpenoid from Protium heptaphyllum suppresses adipocyte differentiation accompanied by down regulation of PPAR $\gamma$ and $\mathrm{C} / \mathrm{EBP} \alpha$ in 3T3-L1 cells. Biomedicine \& Pharmacotherapy 109: 1860-1866.

Moggia C, Graell J, Lara I, Schmeda-Hirschmann G, Thomas-Valdés S \& Lobos GA (2016) Fruit characteristics and cuticle triterpenes as related to postharvest quality of highbush blueberries. Scientia Horticulturae 211: 449-457.

Murthy KSR, Reddy MC, Rani SS \& Pullaiah T (2016) Bioactive principles and biological properties of essential oils of Burseraceae: a review. Journal of Pharmacognosy and Phytochemistry 5: 247-258.

NIST - National Institute of Standards and Technology (2017) NIST standard reference data. Standard Reference Data Act. Available at $<$ https://webbook. nist.gov/chemistry/name-ser/>. Access on 15 October 2017.

Noronha JPC (2001) Metabolitos secundários do fruto de Arbutus unedo L. (Medronho). Dissertação de Doutorado. Universidade Nova de Lisboa, Lisboa. $274 p$.

Ramos MFS, Siani AC, Tappin MRR, Guimarães AC \& Ribeiro JELS (2000) Essential oils from oleoresins of Protium spp. of the Amazon region. Flavour and Fragrance Journal 15: 383-387.

Rüdiger AL \& Veiga-Junior VF (2013) Chemodiversity of ursane- and oleanane-type triterpenes in Amazonian Burseraceae oleoresins. Chemistry \& Biodiversity 10: 1142-1153.

Rüdiger AL, Siani AC \& Veiga-Junior VF (2007) The chemistry and pharmacology of the South America genus Protium Burm. f. (Burseraceae). Pharmacognosy Reviews 1: 93-104.

Satyal P, Powers CN, Parducci VR, McFeeters RL \& Setzer WN (2017) Chemical composition, enantiomeric distribution, and antifungal activity of the oleoresin essential oil of Protium amazonicum from Ecuador. Medicines 4: 70.

SDBS - Spectral Database for Organic Compounds (2017) SDBS-Mass. National Institute of Advanced Industrial Science and Technology (AIST), Tsukuba. Available at $<$ https://sdbs.db.aist.go.jp/sdbs/cgi-bin/ direct frame top.cgi>. Access on 13 December 2017.

Siani AC, Moraes R \& Veiga Junior VF (2017) Toward establishing the productive chain for triterpenebased Amazonian oleoresins as valuable nontimber forest products. Open Journal of Forestry 7: 188-208.

Siani AC, Nakamura MJ, Tappin MRR, Monteiro SS, Guimarães AC \& Ramos MFS (2012) Chemical composition of South American Burseraceae non-volatile oleoresins and preliminary solubility assessment of their commercial blend. Phytochemical Analysis 23: 529-539.

Siani AC, Ramos MFS, Guimarães AC, Susunaga GS \& Zoghbi MGB (1999) Volatile constituents from oleoresin of Protium heptaphyllum (Aubl.) March. Journal of Essential Oil Research 11: 72-74.

Silva ER, Oliveira DR, Melo MFF, Bizzo HR \& Leitão SG (2016) Report on the Malungo expedition to the Erepecuru river, Oriximiná, Brazil. Part I: is there a difference between black and white breu? Revista Brasileira de Farmacognosia 26: 647-656.

Silva JRA, Zoghbi MGB, Pinto AC, Godoy RLO \& Amaral ACF (2009) Analysis of the hexane extracts from seven oleoresins of Protium species. Journal of Essential Oil Research 21: 305-308.

Susunaga GS, Siani AC, Pizzolatti MG, Yunes RA \& Monache FD (2001) Triterpenes from the resin of Protium heptaphyllum. Fitoterapia 72: 709-711.

UNDP - United Nations Development Programme (2012) Equator initiative case studies. Green Life Association of Amazonia (AVIVE), Brazil. Available at $<$ https://www.equatorinitiative.org/ wp-content/uploads/2017/05/case_ 1348160963 EN.pdf $>$. Access on 12 December 2018.

Vieira Júnior GM, Souza CML \& Chaves MH (2005) The Protium heptaphyllum resin: isolation, structural characterization and evaluation of thermal properties. Química Nova 28: 183-187.

Vilegas JHY, Lanças FM, Vilegas W \& Pozetti GL (1997) Further triterpenes, steroids and furocoumarins from Brazilian medicinal plants of Dorstenia genus (Moraceae). Journal of the Brazilian Chemical Society 8: 529-535. 